\title{
La visión de la Historia y el método de Sir Ronald Syme en la obra de Géza Alföldy: algunas consideraciones
}

\author{
The conception of History and the historical method of Sir \\ Ronald Syme in the work of Géza Alföldy: some reflections
}

\author{
Gustavo Alberto García Vivas*
}

\begin{abstract}
RESUMEN
ABSTRACT

El propósito de este trabajo es analizar la visión de la Historia que tenía Sir Ronald Syme y su método historiográfico a través de una serie de trabajos obra de uno de sus mejores y más perspicaces analistas, el profesor Géza Alföldy. Él y Syme mantuvieron una relación personal y profesional durante más de un cuarto de siglo y eso le sirvió a Alföldy para conocer como pocos los entresijos de la obra del Camden Professor de Historia Antigua de la Universidad de Oxford, llegando a ser uno de los más finos comentaristas de la misma. PALABRAS CLAVE: Sir Ronald Syme, Géza Alföldy, Historia The purpose of this paper is to analyze Sir
Ronald Syme's view of History and his
historiographical method through the work
of one of his better commentators,
Professor Géza Alföldy. Syme and Alföldy
kept personal and professional contact for
more than a quarter of a century. Alföldy
gained a close insight into Syme's entire
body of work and eventually became one
of his finest critics. KEYWORDS:

Sir Ronald Syme, Géza Alföldy, Roman History, Historiography.

Recibido el 21 de mayo de 2012. Aceptado el 16 de junio de 2012

\footnotetext{
* Área de Historia Antigua. Universidad de La Laguna. Facultad de Geografía e Historia. Campus de Guajara. 38205- La Laguna Tenerife. Correo electrónico: gusgarvi@gmail.com. El Dr. José A. Delgado Delgado, Profesor Titular de Historia Antigua de la Universidad de La Laguna, leyó una primera versión de este trabajo y me proporcionó una serie de atinadas sugerencias sobre el mismo. Los profesores Susan M. Treggiari (Oxford), Keith R. Bradley (Notre Dame-Indiana, Estados Unidos) y Anthony R. Birley (Düsseldorf), este último discípulo directo de Syme, tuvieron la amabilidad de leer este artículo antes de su impresión final y me proporcionaron valiosas observaciones. Les estoy muy agradecido a todos ellos. En cualquier caso, somos los últimos responsables de las ideas de este artículo.
} 
El historiador alemán de origen húngaro Géza Alföldy (1935-2011), recientemente fallecido en Atenas, fue uno de los mejores y más perspicaces analistas que ha tenido la obra y la concepción historiográfica de Sir Ronald Syme (1903-1989). Syme fue Camden Professor de Historia Antigua en Oxford durante más de veinte años, de 1949 a 1970, y es uno de los más importantes historiadores de la antigüedad romana de todo el siglo veinte ${ }^{1}$.

Ronald Syme nació en Eltham (Nueva Zelanda) en 1903 y destacó ya desde su juventud por sus excepcionales dotes para las lenguas clásicas y modernas. En Oxford desarrolló la mayor parte de su vida docente e investigadora. Fue fellow de Trinity College de 1929 a 1949. De 1942 a 1945 ocupó la Cátedra de Filología Clásica en Estambul. En 1949 pasó al Brasenose College donde sucedió a Hugh Last como Camden Professor hasta su jubilación en 1970. Hasta el final de su vida mantuvo un vertiginoso ritmo de producción como fellow de Wolfson College.

Aunque Géza Alföldy pertenecía a una generación más joven que el neozelandés, ambos hombres trabaron desde 1964 una relación personal y profesional derivada de intereses coincidentes en muchos aspectos de su profesión. El propósito de este trabajo es aproximarnos a la visión de la Historia y el método de Sir Ronald Syme mediante el análisis de los cuatro textos más representativos de la producción de Alföldy en los que analiza las claves de la producción historiográfica del profesor de Oxford.

Los cuatro trabajos, en concreto una amplia recensión y tres artículos, abarcan un período de catorce años. El primero data de 1979 y es una densa reseña de los dos primeros volúmenes de los Roman Papers de Syme (en adelante $R P$ ) que acababan de ver la luz en Oxford en una edición al cuidado de Ernst Badian, uno de los más importantes discípulos del neozelandés². El siguiente, de 1983, es un trabajo de gran relieve publicado en una revista de la Academia de Ciencias de Heidelberg y cuya primera versión fue una conferencia pronunciada por Alföldy en mayo del año anterior ${ }^{3}$. El tercero de los artículos, aparecido en Gerión ese mismo año, es el resultado de una conferencia que el profesor alemán de origen húngaro

1 Sobre la figura de Sir Ronald Syme se han escrito numerosas notas y perfiles biográficos. Entre otros, son especialmente útiles: BOWERSOCK, Glen, «The emperor of Roman History» The New York Times Review of Books, 27-3, 6 de marzo de 1980, pp. 8-13 (en adelante Emperor); BIRLEY, Anthony, «Sir Ronald Syme»», necrológica en The Independent, 7 de septiembre de 1989; CHRIST, Karl, «Ronald Syme», Neue Profile der Alten Geschichte, Darmstad, 1990, pp. 188-247; BOWERSOCK, "Ronald Syme 1903-1989», Proceedings of the British Academy, 84 (1994), pp.539-563 (en adelante Proceedings). Véase también MILLAR, F. «Style abides», JRS, 71 (1981), pp. 144-152; GRIFFIN, Miriam T, «Sir Ronald Syme 1903-1989», JRS, 80 (1990), xi-xiv; ALONSO TRONCOSO, Víctor, «Desesperadamente ajeno: Sir Ronald Syme and The Roman Revolution», Estudios Clásicos, 97 (1990), pp. 77-92 y WISEMAN, Timothy Peter, «Late Syme. A Study in Historiography» en T. P. WISEMAN (ed.), Roman Drama and Roman History, Exeter, University of Exeter Press, 1998, pp.135-152.

2 ALFÖLDY, Géza, «Review-discussion. Ronald Syme, Roman Papers, edited by E. Badian, 2 vols., Oxford, 1979», American Journal of Ancient History, 4 (1979), pp. 167-185 (en adelante Review).

3 ALFÖLDY, «Sir Ronald Syme, Die römische Revolution " und die deutsche che Althistorie», Sitz. Der Heidelberger Akademie der Wissenschaften., Philosophisch-historische Klasse, 1 (1983), pp. 5-42. (en adelante Ronald Syme). 
dictó en Düsseldorf en $1982^{4}$. Por último, nos ocuparemos de un texto publicado por el docente de Heidelberg en la revista italiana Athenaeum en $1993^{5}$.

Al comienzo de la importante reseña publicada en el American Journal of Ancient History ${ }^{\circ}$, con ocasión de la aparición de los dos primeros volúmenes de los $R P$ de los que al final se editaron cinco más, Alföldy se felicita por dicho evento editorial ya que constituye un importante hito para la investigación de la Historia de Roma y reconoce a Badian el mérito a la hora de recopilar casi sesenta trabajos de Syme entre artículos y recensiones. Más si se tiene en cuenta la prolífica producción de Sir Ronald de casi trescientos artículos y más de una veintena de monografías ${ }^{7}$.

Esto nos lleva a la cuestión del período cronológico en el que se inserta el corpus investigador de Sir Ronald. El ámbito temporal de los $R P$ es, escribe Alföldy, el que interesó a Syme durante toda su vida: la historia romana desde el final de la República hasta el tránsito de los siglos IV al V de nuestra era. Más en concreto, el período que va de Julio César hasta Antonino Pío, echando a veces la vista un poco más atrás hasta Mario o Sila y llegando hacia delante hasta la época de la Historia Augusta, fuente a la que prestó especial atención en las décadas finales de su carrera ${ }^{8}$.

\section{SYME Y SUS TEMAS DE INVESTIGACIÓN}

¿Qué temas de investigación le interesaban al neozelandés? Alföldy asegura que el leitmotiv principal de la investigación de Syme, a lo largo de toda su vida, fue el análisis del grupo dominante, la «governing class» y cómo esa élite ejerce el poder, cuál era su mentalidad y cómo interactuaban sus miembros entre sí. Qué intereses y aficiones los definían. En definitiva, cuáles eran los estímulos intelectuales de los gobernantes, entre los que la literatura ocupaba un lugar preeminente. La historia narrativa que hace Syme no debe considerarse en ningún caso, una «histoire événementielle» en el sentido que esta expresión tendría, por ejemplo, para la escuela francesa de los Annales. No, en absoluto: Ronald Syme hace historia política y esa historia política es, al mismo tiempo, historia social. La tesis de Syme como historiador político y social es la que defenderá siempre

4 ALFÖLDY, «La Historia Antigua y la investigación del fenómeno histórico», Gerión, 1 (1983), pp. 39-61 (en adelante Historia Antigua). Un dato: por error tipográfico o de corrección de pruebas, en la parte inferior de la primera página de todos los artículos de ese primer número de la revista se da como año de publicación el de 1984, que corresponde en realidad al año de publicación del segundo número de Gerión.

5 ALFÖLDY, «Two Principes: Augustus and Sir Ronald Syme», Athenaeum, 81 (1993), pp.101-122. (en adelante Principes).

6 ALFÖLDY, Review..., p. 167.

7 Una bibliografía muy completa de Syme desde 1928 hasta los trabajos suyos publicados a título póstumo puede consultarse en el apéndice con el que finalizan estos dos artículos de DEVINE, A.M., «Sir Ronald Syme (1903-1989): A Roman Post Mortem», AncW, 20 (1989), pp. 67-75; e ídem., «Sir Ronald Syme and The Roman Revolution», AncW, 20 (1989), pp. 77-92.

8 Véase n. 6. 
Alföldy a la hora de analizar la Geschichtsbeschreibung del británico. El autor de este trabajo comparte plenamente la tesis del historiador de Heidelberg ${ }^{9}$.

El papel ejercido por la clase dominante en el Imperio Romano: ese es el tema principal de la obra de Syme. Un historiador al que puede aplicársele, en lo referente a su estilo literario, una afortunada frase igualmente atribuible a Edward Gibbon: «He was fortunate in discovering a historical theme of high import that was congenial to his tastes and not beyond his talents ${ }^{10}$.

En el neozelandés el tema de investigación, que atraviesa toda su obra, se mantiene prácticamente invariable durante más de sesenta años. Funciona como un perpetuum mobile recurrente. Puede decirse que todas sus monografías, artículos y recensiones los escribe con el propósito de demostrar el papel fundamental que la oligarquía gobernante ejerce durante toda la historia de Roma.

Las claves sobre cómo Syme se aproxima al hecho histórico nos las proporciona Alföldy en las páginas que componen la recensión antes mencionada $^{11}$, aplicándolas sabiamente a los dos primeros volúmenes de los $R P$.

El profesor de Oxford fue un auténtico especialista en la clasificación y estudio de las carreras políticas de los miembros de la élite. Fue siempre un maestro en la Grundlagenforschung del método prosopográfico, técnica árida y difícil donde las haya $^{12}$. Syme fue quizá el máximo experto de la técnica prosopográfica en su época. En los volúmenes que Alföldy analiza, puede citar los siguientes artículos donde esa maestría queda bien patente: «The wrong Marcius Turbo», Who was Vedius Pollio?» o «Who was Decidius Saxa?»13. Ese interés de Syme en la prosopografía, que inculcó al profesor alemán objeto de este homenaje, le hace estar especialmente atento a la procedencia geográfica de los miembros de la clase dirigente. La epigrafía es fundamental para entender esa excelencia symeana en el método prosopográfico.

El británico y el húngaro tenían en común una serie de aspectos. Entre otras cosas, un origen periférico. Por ello, ambos tenían un gran interés investigador en los senadores y funcionarios provenientes de las provincias del Imperio, lo que Syme vino a denominar «Colonial elites» ${ }^{14}$. Los senadores del sur de la Galia, la

9 ALFÖLDY, Review ..., p. 168.

10 SYME, Ronald, «How Gibbon came to History» en P. DUCREY (ed.), Gibbon et Rome à la lumière de I historiographie moderne, Ginebra, 1977, p.48. (en adelante Gibbon).

11 Véase n. 2.

12 Sobre el método prosopográfico el artículo canónico es el de STONE, Lawrence, «Prosopography» Daedalus, vol. 100, № 1 (1971), pp. 46-79. Más en concreto para la historia de Roma: NICOLET, Claude, «Prosopographie et histoire sociale: Rome et I Italie à I époche republicaine», Annales, 5 (1970), pp. 1209-1228. Sobre Syme y su importancia en el desarrollo de la prosopografía puede consultarse a CABALLOS, Antonio, «La técnica prosopográfica en la Historia Antigua. Ante la pérdida de Sir Ronald Syme», Veleia, 7 (1990), pp. 189-207.

13 SYME, «The wrong Marcius Turbo», JRS, 52 (1962), pp. 87-96; ídem, "Who was Vedius Pollio?», JRS, 51 (1961), pp. 23-30; y «Who was Decidius Saxa?», JRS, 27 (1937), pp. 127-137.

14 A estas élites dedicó Syme un delicioso libro donde practica un notable ejercicio de historia comparada: Colonial élites: Rome, Spain and the Americas, Oxford, 1958 (traducción española: Élites Coloniales. Roma, España y las Américas. Traducción, introducción y notas de A. Caballos, Algazara, Málaga, 1993). 
Narbonense, constituyeron un tema de permanente atención en Syme junto con los de las provincias hispanas, debilidad compartida con Alföldy. En el caso del primero, apunta el sabio de origen magiar, este interés trasluce incluso matices sociológicos y psicológicos ya que Syme defendió siempre que el sistema meritocrático de la época romana imperial dependía tanto de la capacidad del individuo como del encuadre de éste en un grupo o «lobby» de carácter geográfico. Como vemos, las vivencias personales de Sir Ronald y en especial su origen en las antípodas de la metrópoli, poseen una enorme importancia para explicar sus preferencias investigadoras ${ }^{15}$.

Para Alföldy, el ejemplo más acabado que Syme ofrece como representante de la aristocracia romana durante el Imperio lo constituye el homo novus: «the 'new man' from the rising upper classes of 'provincial' Northern Italy and of some provinces who devoted himself with extreme vigour and engagement to the government of the Empire and at the same time to the preservation of the mos maiorum ${ }^{16}$.

La evaluación de las interrelaciones sociopolíticas de los distintos magnates y sus núcleos familiares fueron siempre un tema central en Syme. De ahí, la influencia fundamental del alemán Friedrich Münzer (1868-1942) y del alemán de origen suizo Matthias Gelzer (1886-1974) en el opus symeano. Sobre todo, desde finales de la década de los 40 del siglo XX. Más en concreto desde 1939, año de publicación de The Roman Revolution ${ }^{17}$ (en adelante $R R$ ). Y es que no debemos olvidar que la primera decena de años de actividad investigadora de sir Ronald los dedicó sobre todo a temas de historia militar. Eso es ahora difícil de dilucidar pero cuando La Revolución Romana se publicó, Syme era ampliamente respetado y conocido en los círculos académicos como un reputado historiador militar ${ }^{18}$.

En los dos primeros volúmenes de los $R P$, Syme otorga especial importancia a los Fasti. El propio Alföldy señala la relevancia de esta relación de cónsules y gobernadores provinciales como marco fundamental para cartografiar la historia social del período. Los Fasti son una fuente de primera mano a la hora de iluminar la estructura y el desarrollo de la administración imperial y revelan los cambios que se producen, especialmente a lo largo del siglo I d.C., en la composición de la

15 De hecho, Syme empezó a trabajar en un libro sobre el tema de la condición del provincial en Roma en 1934. Un año más tarde y con el manuscrito casi finalizado, lo dejó aplazado para empezar a trabajar en The Roman Revolution. Ese libro fundamental para entender al Syme joven ha sido magníficamente editado y publicado en 1999 por Anthony Birley: SYME, The Provincial at Rome and Rome and the Balkans 80 BC-AD14, A. Birley (ed.), University of Exeter Press, 1999.

16 ALFÖLDY, Review..., p.170.

17 The Roman Revolution es, como veremos a lo largo de este trabajo, una obra fundamental en la historiografía del siglo XX. Ha conocido numerosas traducciones a diversas lenguas. La traducción española la llevó a cabo el añorado Antonio Blanco Freijeiro: La Revolución Romana, Taurus, Madrid, 1989. La editorial Crítica reeditó la obra en 2010 sin cambio alguno en la traducción llevada a cabo por Blanco y con un breve prólogo de Javier Arce.

18 Arnaldo Momigliano alude crípticamente a esta evolución de Syme en su conocida y temprana reseña a $R R$ publicada en JRS, 30 (1940), p. 75: «It is premature to guess how far Mr. Syme will go in this evolution of a moralist historian from a first-class researcher in military history » (la cursiva es nuestra). 
clase gobernante. Como ejemplos del trabajo de Syme en este aspecto, su recensión a la obra de Attilio Degrassi Fasti Consolari dell Imperio Romano o su brillante trabajo sobre los consulados detentados por los legados de las provincias pretorias in absentia ${ }^{19}$. Pero, como advierte el profesor de origen magiar: «Syme $s$ Roman History is not identical with the whole history of Rome»²0. Según Alföldy, hay diversos aspectos de la historia romana que a Syme no parecen interesarle: la religión, la economía, los estratos menos favorecidos de la sociedad o el estudio del derecho romano - Staatsrechts-.

Nosotros disentimos en parte. A diferencia de Alföldy, creemos que Syme se sintió atraido por el estudio de ciertas cuestiones religiosas e incluso dedicó a estos temas una monografía, bien es cierto que desde el punto de vista prosopográfico $^{21}$.

Ahora bien, es cierto que entre las prioridades del neozelandés no estaba el estudio del lenguaje artístico y sus símbolos. De hecho, como bien apunta Alföldy en su artículo de $1993^{22}$, habrá que esperar a la aparición del libro fundamental de Paul Zanker Augustus und die Macht der Bilder ${ }^{23}$, para encontrar algo equivalente a la aparición de $R R$ en la especialidad de la Historia del Arte.

Casi contemporáneamente a la publicación de $R R$ se publicaron dos importantes estudios del húngaro Andreas Alföldi (1895-1981), que en opinión de Alföldy que comparto, poseen una importancia similar para la investigacion de determinados aspectos del Principado, comparable a los escritos de Mommsen o del propio Sir Ronald Syme. En ambos trabajos, de una gran transcendencia, se analizan aspectos de las «imágenes» y los símbolos del período usando la evidencia arqueológica y numismática en combinación con las fuentes literarias y epigráficas ${ }^{24}$.

La publicación en 1987 de la monografía de Zanker supuso una auténtica revolución. Toda una catarsis ${ }^{25}$. Alföldy está de acuerdo con que Augusto no quiso erigir una «republikanische Scheinfassade» para engañar a los romanos sino que ideó y puso en práctica un programa de gobierno de horizontes amplios y novedosos. Un programa de renovación general. Un auténtico «back to basics», basado en convicciones políticas y religiosas. Y ese estimulante programa de «imágenes»,

19 SYME, «Review of A. Degrassi I Fasti Consolari dell' Impero Romano dal 30 Avanti Christo al 613 Dopo Christo», JRS, 43 (1953), pp. 148-161. Ídem., «Consulates in absence» JRS, 48 (1958), pp. 1-9.

20 ALFÖLDY, Review, p. 177.

21 SYME, Some Arval Brethren, Oxford, 1980. Para un punto de vista similar al nuestro, veáse la magnífica aportación de SCHEID, John, «Ronald Syme et la religion des Romains» en Entretiens sur L Antiquité classique, XLVI: La Révolution Romaine après Ronald Syme: Bilans et perspectives, Fondation Hardt, 2000, pp. 39-72.

22 ALFÖLDY, Principes..., p. 112.

23 ZANKER, Paul, Augustus und die Macht der Bilder, Múnich, 1987 (en adelante Augustus). Una de las primeras recensiones publicadas sobre el libro tras su traducción al español en 1992 fue la nuestra: GARCíA VIVAS, Gustavo, «Imago Augusti», Tempus, 8 (1994), pp. 87-93.

24 ALFÖLDI, Andreas, «Die Augestaltung des monarchischen Zeremoniells am römischen Kaiserhofe» RM, 49 (1934), pp. 1-118 e ídem, «Insignien und Tracht des römischen Kaiser», RM, 50 (1935) pp. 1- 171.

${ }_{25}$ Véase en GARCÍA VIVAS, op. cit., (n. 23), p. 88, el elogio que le tributó al libro A. WallaceHadrill en su reseña en JRS, 79 (1989), p. 157. 
propuesto desde arriba por la «governing class», recibió por parte de los romanos de todos los grupos sociales una respuesta positiva de carácter espontáneo. Esa es la tesis del libro de Zanker. Y esa renovación llegó incluso hasta las inscripciones y el arte epigráfico. Escribe Alföldy: «the epigraphic culture of the Romans underwent a revolutionary transformation under Augustus, becoming imperial both in the sense of its function in the service of the imperial monarchy and in the sense of its spreading throughout the whole Empire during a single generation»26.

Esa misma generación, la que vivió bajo Augusto, fue testigo de una transformación radical de las formas artísticas. El Princeps y sus consejeros estaban convencidos de las virtudes de su programa de gobierno, y lo presentaron e implementaron en público bajo diversas formas, estudiadas por Zanker en su obra. Lo hicieron sin un sentido de la «propaganda» en la acepción más moderna del término, sino casi espontáneamente a modo de «ensayo y error». El resultado fue de una consistencia y un éxito admirables.

Si bien es cierto, como nos dice Alföldy, que las formas artísticas nunca interesaron demasiado a Syme, en su última gran obra publicada antes de morir, encontramos una clara definición de lo que fue la «propaganda» augustea:

"There exist propaganda in vacuo", where competition is absent, the audience passive or already won over: not arts of persuasion, but the exhibition of power and beneficence. (...) Like sumptuary laws or state-enforced morality, a programme of indoctrination would arouse resentment and disbelief. There was a simple remedy: leave it to the educated class to devise formulations or acceptance. Willing agents were to hand, some convinced and some ingenious, as well as the falsi et festinantes' ${ }^{27}$.

Ni en palabras de Paul Zanker, apunta Alföldy en un juicio penetrante que comparto plenamente ${ }^{28}$, se pudo haber formulado de forma más certera la tesis zankeriana sobre la efectividad de la autorepresentación del Principado en base a su aceptación espontánea por las masas. Las líneas anteriores son reveladoras. Y es que en la producción del «último» Syme se observa una sensibilidad más y más creciente por acercarse, si cabe tangencialmente, a los nuevos caminos abiertos en la investigación del Principado, especialmente en aspectos ideológicos y, en menor medida, artísticos.

\section{SYME, SU MÉTODO Y SU CONCEPCIÓN DE LA HISTORIA}

Alföldy señala que la concepción de la Historia de Roma que tenía Ronald Syme se define en el que quizá sea su pasaje más citado de $R R$ : «In all ages,

${ }^{26}$ Véase n. 22. Y especialmente sobre este tema, el fundamental artículo de ALFÖLDY, «Augustus und die Inschriften: Tradition und Innovation. Die Geburt der imperialen Epigraphik», Gymnasium 98 (1991), pp. 298-324.

${ }_{27}$ SYME, The Augustan Aristocracy, Oxford, 1986, pp. 439 y 441 (en adelante $A A$ ).

28 ALFÖLDY, Principes..., p.120. 
whatever the form and name of government, be it monarchy, republic or democracy, an oligarchy lurks behind the façade»29. Podemos afirmar que, con mínimas variantes de matiz, esta frase programática rige toda la producción historiográfica de Syme durante más de sesenta años desde 1928, año en el que publica su primer artículo en el Journal of Roman Studies ${ }^{30}$ hasta su muerte acaecida en 1989.

Por lo tanto, la omnipresencia de la oligarquía, de una élite gobernante que maneja los destinos de la historia de Roma independientemente de la forma de gobierno existente en la ciudad del Tíber es una idea intrínseca a la concepción symeana de la Historia. Señala también Alföldy otras dos constantes presentes en la obra del profesor de Oxford. En primer lugar, Ronald Syme era sobre todo un historiador del poder. Del poder y la lucha por conseguirlo. De la visión del poder en Roma manejado a fines de la República por distintas facciones enfrentadas entre sí y después controlado directamente por la figura del emperador. En segundo lugar, el enorme interés de Syme en explorar y dilucidar los gustos literarios de la aristocracia romana. Poseedor él mismo del más exquisito estilo literario, su peculiar «high style ${ }^{31}$, Syme era un apasionado de la literatura, en especial de la literatura francesa del siglo XIX. Las fuentes literarias ocupan un lugar determinante en toda su producción. Desde Salustio y Tácito, hasta Plinio el Joven o Veleyo. Pero también Tucídides y Gibbon, Macaulay y Toynbee han merecido su atención ${ }^{32}$. Alföldy captó como pocos una constante permanente en la obra de Syme: Literatura y Historia, Filología Clásica e Historia Antigua convergen una y otra vez. Son un todo. Dos caras de la misma moneda. La literatura como parte de la tradición histórica. La literatura también como transmisora de hechos y eventos y como vehículo para la expresión de ideas y comportamientos.

Valgan dos ejemplos, los poemas amorosos de Ovidio nos hablan de guerra y de política. Y son, a la vez, un poderoso medio de expresión del clima moral y la mentalidad que permeaban la aristocracia augustea ${ }^{33}$. De igual manera, el discurso que Tácito transcribe en sus Anales sobre la concesión del ius honorum a la aristocracia gala nos habla, en atinado juicio de Syme, de la necesidad de revitalizar la aristocracia senatorial reclutando novi homines de las provincias ${ }^{34}$.

"Subject, method and tendency», indica Alföldy ${ }^{35}$. El tema, el método y la influencia. Estos son los tres asuntos que han generado siempre mayores disensiones entre partidarios y oponentes de Syme y su modo de ver la historia.

29 SYME, RR, Oxford, 1939, reimp. 1960, p. 7.

30 ídem., «Rhine and Danube Legions under Domitian», JRS, 18 (1928), pp. 41-55.

31 MILLAR, op. cit., (n. 1), p. 146.

32 Sobre Tucídides, véase SYME, «Thucydides», PBA, 48 (1962), pp. 39-56 (en adelante Thucydides). Sobre el resto de la relación: ídem., "Three English Historians: Gibbon, Macaulay and Toynbee», Emory University Quaterly, 18, (1962).

33 SYME, History in Ovid, Oxford, 1978, pp. 72 y 199 s.

${ }^{34}$ Ídem., Ten studies in Tacitus, Oxford, 1970, p. 26 s. (en adelante Studies ...); y Tacitus, Oxford, 1958, pp. 317 ss.

35 Principes..., p. 105. 
Ya en su temprana y fundamental crítica a $R R$, Arnaldo Momigliano se hace eco de las importantes limitaciones que comportaba el método prosopográfico ${ }^{36}$. Las observaciones de Momigliano son correctas en buena medida. Sin embargo, la proposopografía en Syme es más que un fin en si misma. Es un método llevado a sus más altas cotas de excelencia. En un autor como Syme que era, ante todo, un historiador de la política y un historiador social. Así lo deja entrever Sir Ronald en el que quizá sea el trabajo de su carrera dotado con una mayor carga teórica ${ }^{37}$.

El Camden Professor dejó muy claras cuáles eran las características que, a su juicio, debe poseer un buen historiador: en primer lugar, erudición. Ya lo dice Syme parafraseando a Gibbon: «diligence and accuracy»38. También familiaridad con los temas de la alta política y buen conocimiento de los entresijos de la naturaleza humana. Y la importancia de viajar y conocer distintas culturas. Tanto Sir Ronald como el profesor Alföldy fueron ambos impenitentes viajeros. Recorrieron una buena cantidad de países europeos y africanos intentando trabajar in situ en las inscripciones originales allí donde se encontraran. O simplemente por el mero placer de viajar. De hecho, Géza Alföldy falleció cuando se encontraba en la capital griega, en concreto visitando la Acrópolis, en vísperas de recibir un doctorado honoris causa en la Universidad de Corfú 39 .

Alföldy señala que Ronald Syme no dedicó jamás un artículo a la descripción teórica de su método de trabajo. Esta afirmación es de una gran importancia. El método de Syme es bien simple: «hard work and accuracy» ${ }^{40}$. Esto es, el análisis profundo y meticuloso de las fuentes y los hechos. Por supuesto, su discurso historiográfico está plagado de ideas pero éstas no deben confundirse con la teoría abstracta. Lo que se necesita para escribir bien Historia, según Syme es: "education, hard work and accuracy, composition and style, familiarity with politics and human nature». O sea, inteligencia: "intelligence is the supreme virtue ${ }^{41}$.

Esas cualidades hacen que su forma de escribir, el antes mencionado «high style», no tenga equivalente en la prosa histórica del siglo XX. Conviene citar llegados a este punto la bellísima descripción que Mason Hammond hiciera allá por 1959 del estilo literario de Syme: «though often elliptical, staccato, and occasionally difficult to follow, is lively, stimulating and Tacitean» ${ }^{42}$.

En efecto, Tácito es uno de sus modelos. Como bien señala Alföldy, Syme es el último de los grandes historiadores en una línea que comienza con nombres de la

36 MOMIGLIANO, op. cit. (n. 18), pp. 77-78.

37 SYME, Ronald, «Oligarchy at Rome. A Paradigm for Political Science», Diogenes, 141 (1988), p. 65.

38 SYME, Gibbon..., p.52.

39 Debo este dato a la amabilidad del Dr. José A. Delgado Delgado, Profesor Titular de Historia Antigua de la Universidad de La Laguna. Además, lo proporciona el Prof. Juan Manuel Abascal en la necrológica que acaba de publicar en Veleia sobre el Prof. Alföldy, cf (n. 99), p. 319.

40 SYME, Thucydides..., p. 41.

41 Ibídem., p.56.

42 HAMMOND, Mason, «Review of R. Syme Tacitus «, The American Historical Review, 64, no 4 (1959), p. 916. 
talla de Salustio, Polión o Livio, pasando por Tácito y mucho después Gibbon y que desemboca en Theodor Mommsen. Citando una vez más a Alföldy, su estilo «imitates the style of the ancient literary sources which he uses, and thus they reflect from the first something of the mentality of that élite in which Syme is interested» ${ }^{43}$.

Se observa una falta de teoría palpable en The Roman Revolution en particular, y en general en toda la obra symeana. Este hecho puede ilustrarse tomando como ejemplo el término «revolución». Sabemos que su fuente para el uso de este término fue Edward Gibbon ${ }^{44}$. Pero en ninguna parte de $R R$ se asegura que en el período tratado en él, o sea desde el 60 a. C. hasta el 14 d. C., se produzca una revolución de acuerdo con la definición canónica que nos proporcionó, por ejemplo, Alfred Heuss en $1956^{45}$.

En opinión de Syme, la «revolución» que se produjo en Roma en el período fue "a violent transference of power and of property" ${ }^{46}$ en el que la nobleza republicana tradicional, diezmada por décadas de guerras civiles y por la terrible coyuntura de las proscripciones, perdió su estatus de «governing class», siendo sustituida por una nueva élite reclutada en los municipios y las colonias de la península italiana y ciertas provincias, Narbonense e Hispania especialmente. Este grupo formó el núcleo duro del partido cesariano y la base de apoyo desde el que el joven Octaviano se aupó al poder. Ese proceso, escribe Alföldy, constituye para Syme la «revolución romana» ${ }^{47}$.

El vocablo «revolución» posee en Syme una función más semántica que otra cosa. De hecho, no solo denomina así al proceso que acabamos de describir. Para Syme, "es gibt recht unterschiedliche Revolutionäre und Revolutionen»48. De hecho, emplea la palabra un buen número de veces a lo largo de $R R$. La misma casuística se produce con otros términos que aparecen en la obra.

Para el docente de Oxford, la Historia es en gran medida la historia de los destinos de las personas. Se detecta en él, asegura Alföldy, una intensa preocupación por el destino de los individuos. De los individuos pertenecientes al grupo que detenta el poder. A los aristócratas. Pero el autor no hace ni un intento por definir a qué se conocía en Roma como «aristocracia». Es sintomático que, de entre todos los historiadores alemanes, Matthias Gelzer ejerciera una influencia especial en Syme con su breve pero estimulante Die Nobilität der römischen Republik ${ }^{49}$. El hecho es

43 ALFÖLDY,Review..., p.176.

44 ALFÖLDY, Principes..., p.115.

45 HEUSS, Alfred, «Der Untergang der Römischen Republik und das Problem der Revolution «, Historische Zeitschrift, 182 (1956), p. 1.: „Revolution... ist der gewaltsame Austrag eines Klassengegensatzes, in dem eine unterdrückte bzw. von der Herrschaft ausgeschlossene Klasse den offenen und illegalen Kampf um ihre Freiheit und damit um den dominierenden, um nicht zu sagen ausschliesslichen Einfluss auf den Staat unternimmt«.

46 SYME, $R R$, p. vii.

47 ALFÖLDY, Ronald Syme..., p. 12.

48 Ibídem., p. 13.

49 GELZER, Matthias, Die Nobilität der römischen Republik, Leipzig, 1912 (traducción inglesa e introducción de R. Seager, The Roman Nobility, Oxford, 1969). 
llamativo ya que esta obra contiene un análisis de carácter estructuralista, que no prosopográfico, de la oligarquía romana.

Pero esa falta de análisis estructural no se cierne sólo sobre la clase gobernante. Tampoco vemos en $R R$, añade Alföldy, un análisis del Senado o de las magistraturas. Ni siquiera una gran preocupación por desentrañar las claves de la Verfassung del Principado augusteo. Vale la pena citar textualmente a nuestro homenajeado:

«Deshalb ist die Entstehung des Prinzipates — mit dem Jahre 23 v. Chr. als dem bedeutendsten Markstein auf einem langen Weg, der zum Sieg der Revolution und zur Errichtung einer neuen Regierung führte - nach Syme kaum ein Wendepunkt in der römischen Geschichte: At Rome, it did not mark an era in dating; in the provinces it passed almost unnoticed „50.

¿Quiénes son entonces estos individuos sobre cuyos destinos escribe Sir Ronald esta obra? Desde luego, no las clases populares: libertos y esclavos. Tampoco el ejército y la soldadesca. Alföldy relata una anécdota personal cuando le comentó a Syme que el primer artículo suyo que había leído de estudiante fue, a su vez, el primero que el británico había publicado: «Rhine and Danube Legions under Domitian»51. Sir Ronald repuso que posteriormente en su carrera se había sentido siempre más interesado por la figura de cualquier legado de legión senatorial que por toda una legión completa. Otro episodio de corte similar: en una carta escrita a Syme, Alföldy le interpeló por qué nunca escribía sobre los esclavos y las clases menos favorecidas: «it bores me». Esa fue la rotunda y sincera respuesta que recibió del Camden Professor ${ }^{52}$.

La descripción y caracterización de los protagonistas históricos era algo esencial para Syme. En los años 30 del pasado siglo en los países donde habían triunfado los sistemas totalitarios se desarrolló un calculado culto al individuo, ya fuera éste el Fuhrer, el Duce o el Caudillo. Un hito importante en este proceso, en Italia en concreto, fue la Mostra Augustea que conmemoró en Roma en 1937, de la mano de Benito Mussolini, el bimilenario del nacimiento de Augusto ${ }^{53}$.

En esos años se publicaron una serie de monografías que proporcionaban una descripción bastante benévola de Augusto y de su reinado. En Alemania, la más influyente fue la obra escrita por el profesor de Berlín, Wilhelm Weber (18821948) ${ }^{54}$. En su artículo de 1993 Alföldy profundiza en esta cuestión. Su opinión sobre este asunto, que comparto, es que la producción y publicación de $R R$ puede entenderse en gran medida como una respuesta a todas estas publicaciones laudatorias, a todo este corifeo de alabanzas que diversos historiadores alemanes

\footnotetext{
50 ALFÖLDY, Ronald Syme..., p.15

51 Véase n. 30.

52 Carta de Syme a Alföldy de 22 de febrero de 1981. (apud ALFÖLDY, Ronald Syme..., p.17).

53 Sobre la Mostra Augustea véase la excelente monografía de SCRIBA, Friedemann, Augustus im Schwarzhemd?: die Mostra Augustea della Romanita in Rom, 1937/38., Frankfurt, Lang, 1995.

${ }^{54}$ WEBER, Wilhelm, Princeps. Studien zur Geschichte des Augustus I, Stuttgart-Berlin, 1936.
} 
e italianos escribieron adulando la figura de un Augusto del que Sir Ronald ya poseía una opinión poco favorable incluso antes de $1937^{55}$.

Concluimos este apartado. La perspicacia de Alföldy queda de manifiesto cuando asegura que, en lo referente a Syme, su manera de trabajar es rechazar todo sistema metodológico basado en premisas teóricas: «To insist on the 'die gesunde Methode' is tedious. And it may be superfluous. Nor is the cult of methodology always a strength»56. La Historia para Syme se explica por sí misma y hacer historia rigurosa es hacerla con exactitud y trabajo duro y narrarla con el mejor estilo literario posible ${ }^{57}$.

Para Alföldy, The Roman Revolution puede calificarse como modelo de historia inductiva, como una obra modélica que parte de las fuentes para reconstruir todo un momento histórico y llega a plantear que la conocida frase de Syme al comienzo del libro ${ }^{58}$ funciona como idea e incluso más, como «modelo teórico de investigación» ya que «por él están condicionados en su obra el planteamiento general, el método, los resultados más importantes y no menos la narrativa»59.

\section{SIR RONALD SYME Y LA RECEPCIÓN E INFLUENCIA DE THE ROMAN REVOLUTION EN LA HISTORIOGRAFÍA ALEMANA}

Géza Alföldy se alinea con Sir Fergus Millar cuando escribe que el Tacitus, publicado dos décadas después de $R R$, es el trabajo de mayor influencia de Syme $^{60}$. Se me permitirá disentir de esta aseveración. Quizá sea así para el mundo académico especializado y ni siquiera estamos muy seguros de esto. Pero lo cierto es que el impacto de La Revolución Romana ha sido «tremendous», por usar una expresión de uno de los pupilos más próximos a Syme escrita cuarenta años después de la publicación del libro ${ }^{61}$. Sin duda alguna, mucho mayor que el del Tacitus y no solo entre los entendidos sino especialmente entre los lectores de Historia no profesionales.

Vayamos por partes, en primer lugar un breve apunte sobre la relación SymeAlföldy. El hecho de que el profesor de origen húngaro fuera el académico elegido para pronunciar la primera «Ronald Syme Lecture» que tuvo lugar en el Wolfson College de Oxford el 21 de noviembre de 1991, da una idea de la intensa relación académica y personal que ambos investigadores mantuvieron durante más de un cuarto de siglo. El propio Alföldy lo explica muy claramente: «Having known Sir Ronald for almost 25 years I was very glad to undertake this task (...). I owe him a great deal, both concerning the choice of my subjects and the historical method. But

\footnotetext{
55 ALFÖLDY, Principes ..., p. 104.

56 SYME, Ronald, The Historia Augusta. A call for clarity, Bonn, 1971, p. 5.

57 ALFÖLDY, Historia Antigua ..., p. 49.

58 Véase n. 29.

59 ALFÖLDY, Historia Antigua ..., p. 52.

60 ALFÖLDY, Principes..., p. 108

${ }^{61}$ BOWERSOCK, Emperor..., p. 8.
} 
I ascribe the honour given to me by the invitation principally to the fact that I represent a German University which is proud to have counted Sir Ronald among its friends for almost four decades»62. Su artículo de 1993 es, en esencia, la conferencia que Alföldy dictó en esa feliz efemérides.

La aportación de Alföldy de $1983^{63}$ se abre con dos rotundos juicios sobre The Roman Revolution, efectuados por dos eximios especialistas ingleses, D.R. Shackleton-Bailey ${ }^{64}$ y Sir Fergus Millar ${ }^{65}$. Ambos poseen un carácter laudatorio. El tercero que recoge Alföldy, en tono negativo, es el del alemán H.E. Stier ${ }^{66}$. Resulta interesante, añade el profesor de Heidelberg, que la valoración negativa de $R R$ esté hecha por un alemán ya que, a primera vista, el libro parece tener más puntos en común con la tradición historiográfica alemana que con la anglosajona. Sin embargo, no ha ocurrido así.

Desde su aparición cuatro días después de que Gran Bretaña declarara la guerra a Alemania, en concreto el 7 de septiembre de $1939^{67}$, la $R R$ supuso una novedad historiográfica de primer orden. Como bien apunta Alföldy ${ }^{68}$, el tema del libro había sido abordado incesamente, pero su enfoque y estilo, así como la metodología usada: no del todo prosopográfica, no del todo historia factual sino una soberbia mezcla de ambos; hacían de la monografía algo del todo novedoso. Sin embargo, sólo a comienzos de la década de los cincuenta el libro comenzó a ser ampliamente conocido en Alemania. Con seguridad, el conflicto bélico tuvo que ser un factor a tener en cuenta para esta recepción tardía. De hecho, la primera edición en alemán es de $1957^{69}$.

En la Alemania de los años 30 y 40 del siglo pasado, de forma similar a lo que sucede hoy en nuestro país, la Historia Antigua y la Filología Clásica eran disciplinas diferenciadas. Sin embargo, a Alföldy no se le escapa un importante detalle: cuando leemos $R R$ es difícil dilucidar si nos encontramos ante el trabajo de un historiador o ante el de un filólogo. Para Syme ambas disciplinas iban de la mano y formaban un todo armonioso. Su dominio de ambas era prodigioso. Llama poderosamente la atención el uso tremendamente moderno de los textos antiguos por parte del neozelandés, como muy bien apuntara A. Rüstow en la primera reseña de la obra que se publicó en alemán ${ }^{70}$.

62 ALFÖLDY, Principes..., p.101.

63 ALFÖLDY, Ronald Syme..., p. 5.

64 SHACKLETON-BAILEY, D.R., «The Roman Nobility in the Second Civil War», The Classical Quaterly, 10 (1960), p. 266.

65 MILLAR, op. cit. (n. 1), p. 146.

66 STIER, H.E., «Augustusfriede und Römische Klassik«, ANRW II.2, Berlin-New York, 1975, pp. 9 y 11.

67 El profesor Birley me ha proporcionado la fecha exacta.

68 ALFÖLDY, Ronald Syme..., p. 8.

69 SYME, Die Römische Revolution. Machtkämpfe in antiken Rom, Stuttgart, 1957. El primer ejemplar que se vio en Heidelberg de $R R$ lo trajo de Suiza el historiador Walter Schmitthenner, cf.: MALITZ, Jürgen, «Walter Schmitthenner» Gnomon, 71 (1999), 2, p. 175. n.3.

70 RÜSTOW, A., « Die Römische Revolution und Kaiser Augustus« Rev. De la Faculté des Sciences Economiques de I Université d Istanbul, 5 (1944), pp. 244 ss. 
Alföldy observa muy agudamente una influencia más que posible en Syme a la hora de escribir $R R$, aunque éste nunca lo reconociera: el libro de Sir Lewis Namier The Structure of Politics at the Accession of George III, publicado en $1929^{71}$. Diez años antes de que viera la luz The Roman Revolution. Con fino criterio, el alemán cree que Arnaldo Momigliano tiene toda la razón en resaltar la influencia de Namier y de su atmosfera intellettuale` en Ronald Syme y su conocida obra ${ }^{72}$. Momigliano dice de Syme que ha «namierizzato la costituzione di Augusto» 73 .

Como hemos apuntado más arriba en nuestro trabajo, en el ánimo de Syme a la hora de escribir el libro influyó el auge de los fascismos en Europa e incluso la nueva constitución de la Unión Soviética promulgada por Stalin en 1936. Pero la publicación de La Revolución Romana, que tiene su germen en unas conferencias dictadas por el fellow del Trinity College en el verano del 37, fue en gran medida una reacción contra la visión optimista del primer emperador de Roma y de su reinado, visión imperante en ese momento en toda la historiografía alemana y británica sobre el período. La forma que Syme adoptó para mostrar su profundo desacuerdo contra «normal Anglo-Saxon attitudes» que reverenciaban a Augusto "as the archetype of the good headmaster, firm and serene, who seldom has to exert the vast authority he holds in reserve» ${ }^{74}$.

El estallido del hecho bélico tuvo una influencia decisiva en la prisa de Syme por publicar su libro. En gran parte, como respuesta personal del scholar de talante liberal que, en su paradisíaca y tranquila atalaya de Oxford, supo ver con rapidez las negras nubes que los totalitarismos entonces en auge iban a cernir sobre el continente europeo.

Pocos especialistas conocen que el original de $R R$ fue dado a la Clarendon Press sin demasiadas correcciones por parte de Syme en las fechas en que comenzaba la guerra y que, en cierto modo, presionó a los editores para que el libro viera la luz con la mayor rapidez posible. Asimismo, en las sucesivas ediciones de la obra el neozelandés no corregiría sino muy pequeños detalles del texto original de 1939, manteniendo prácticamente igual todo el texto ${ }^{75}$.

El impacto de $R R$ incluso durante la guerra en el Reino Unido y los países de lengua inglesa fue enorme. A escala internacional, el libro empezó a ser valorado

71 NAMIER, Lewis, The Structure of Politics at the Accession of George III, Londres, 1929. Hemos manejado la segunda edición de 1957.

72 ALFÖLDY, Ronald Syme..., pp. 10 y 11.

73 MOMIGLIANO, Arnaldo, Introduzione a Ronald Syme.The Roman Revolution, traducc. Italiana, Torino, 1962, p.X = Terzo Contributo alla storia degli studi classici e del mondo antico, Roma, 1966, p. 730. Anthony Birley me hace notar lo extendida que se encuentra esta idea que, según me indica, carece por completo de fundamento.

74 SYME, «History or Biography. The case of Tiberius Caesar» Historia, 23 (1974), p. 482.

75 Sir Fergus Millar, discípulo directo y amigo personal de Syme, además de sucesor en la Cátedra Camden desde 1984 a 2002, me proporcionó estos datos en un encuentro mantenido en el Oriental Institute de Oxford en agosto de 2011. 
desde principios de la década de los 50. La obra creó escuela y como ejemplos Alföldy menciona ${ }^{76}$ las investigaciones de Howard H. Scullard ${ }^{77}$ y Lily Ross Taylor ${ }^{78}$, aunque Syme nunca se preocupó por formar una «escuela» en el sentido continental que posee el término. También Ernst Badian se alinearía en este grupo $^{79}$

En Alemania sin embargo, y como bien apunta Alföldy, la influencia de $R R$ en los años inmediatamente posteriores a su publicación estuvo lejos de ser importante. Las primeras recensiones en lengua alemana la firman, la primera A. Rüstow cuya especialidad era la historia económica ${ }^{80}$. La segunda fue obra de W. Ensslin, que en doce páginas hace un detallado análisis capítulo por capítulo. Sin embargo, tan sólo hace un breve comentario sobre el método del libro y limita a una frase su evaluación general de la obra ${ }^{81}$. Finalmente, H.E. Stier en un volumen colectivo sobre la época de Augusto produjo una reseña bastante desfavorable del libro rechazando violentamente tanto el método prosopográfico usado en él, como las consideraciones que Syme hace sobre el Princeps ${ }^{82}$.

En el país germano, dos grupos o «escuelas» de investigadores se han impregnado de manera especial de la influencia de $R R$. El primero de estos grupos fue el formado por Hans Schaefer (1906-1961), Walter Schmitthenner (1916-1997), el politólogo Hans Buchheim (1922-) y Peter Sattler (1930-1961), trágicamente fallecido junto a Schaefer en Ankara en accidente aéreo. Estos estudiosos se dedican principalmente a la historia política en el momento del ascenso de Octaviano y el establecimiento del Principado. Siguen muy de cerca el punto de vista de Syme pero han intentado ir unos pasos más allá, tratando de comprender el proceso político en su conjunto. Este grupo, que podemos denominar «escuela de Heidelberg», quiere ampliar y complementar, que no corregir, la imagen symeana de este período.

Algo muy distinto ocurre con la segunda escuela en la que se percibe la influencia de Syme. Es la encabezada por Christian Meier (1929-), uno de los historiadores de Roma más importantes en Alemania actualmente, que también fue discípulo de Schaefer. En sus trabajos, en especial en su obra más conocida Res publica amissa ${ }^{83}$, se pregunta hasta qué punto puede considerarse la existencia en Roma de facciones políticas permanentes o «partidos» dentro de la clase dirigente. Hay, por tanto, una crítica frontal a lo que la historiografía alemana ha denominado la «Faktions-theorie» defendida principalmente por Syme, Scullard o Ross Taylor.

${ }^{76}$ ALFÖLDY, Ronald Syme..., p. 25.

77 SCULLARD, Howard H., Roman Politics 220-150 BC, Oxford, 1951.

78 ROSS TAYLOR, Lily, Party Politics in the Age of Caesar, Berkeley-Los Angeles, 1949.

79 Aunque de origen austriaco, Badian pasó su juventud en Nueva Zelanda. Véase su obra más representativa: Foreign Clientelae 264-70 B.C., Oxford, 1958.

80 RÜSTOW, op. cit., (n. 70).

81 ENSSLIN, Wilhelm, Besprechung «The Roman Revolution» Historia 1 (1950), pp. 128-139.

82 STIER, op. cit., (n. 66), pp. 3 y 6.

83 MEIER, Christian, Res Publica Amissa. Eine Studie zu Verfassung und Geschichte der späten römischen Republik, Wiesbaden, 1966, nueva edición de 1980, pp. 182 ss. 
No creo que Syme defendiera en $R R$, en particular y en toda su obra en general, un concepto «rígido» e inmanente de facción o partido como pretende Meier. Este aspecto está más presente tanto en Scullard como en Ross Taylor. En cualquier caso, según Meier, éstos fundamentan su tesis en las fuentes, en las que no se dice ni una sola palabra sobre estas facciones. Su crítica no es tanto al método prosopográfico en si, sino a la naturaleza de su aplicación. Alföldy señala en su artículo de $1983^{84}$ que no es ése el lugar para demostrar quién de los dos: Syme o Meier, tiene razón. Y cede la palabra a otro «mandarín» de la Historia Antigua, en este caso el americano de origen austríaco Erich S. Gruen, en una larga cita que vale la pena recoger en su totalidad:

«It will not be obligatory to select between these two alternatives. The former (Syme) ignores significant changes which Roman society and politics had undergone since the era of the Gracchi. Links among noble houses cannot by themselves explain the course of politics. Too many other elements, social, economic and personal, permeated the scene. In a constantly changing political climate, those links did not possess consistency or endurance. The alternative view, howewer, (Meier) would appear to deny all structure to Roman politics. Aristocratic families continued to form marriage connections, to adopt relatives and friends, to flaunt their amici, and to feud with their inimici. It would be foolish to imagine that these maneuvers possessed no political connotations» 85 .

Alföldy sugiere que la recepción plena y eficaz en Alemania del contenido y de la carga de profundidad historiográfica que contiene $R R$ se hizo patente solo bien entrado el siglo XX. En 1993, está en condiciones de asegurar, a diferencia de lo que sucedía diez años antes, que la influencia de $R R$ en el mundo académico alemán es muy similar al del resto de los países. Para el docente de Heidelberg, en este cambio de tendencia han influido decisivamente dos trabajos: el magnífico capítulo de Karl Christ dedicado a Sir Ronald en una obra de $1990^{86}$ y la aparición del libro de Paul Zanker, que ya hemos comentado ${ }^{87}$.

Alföldy asegura que, en contra de la communis opinio, existe un hilo conductor que une al Gibbon de Decline and Fall con Syme. En ese hilo conductor, el profesor de Heidelberg señala como dos nexos importantes las grandes figuras de Barthold Niebuhr y Theodor Mommsen, en concreto el «primer» Mommsen, el autor de los tres primeros volúmenes de la Römische Geschichte (1854-1856) ${ }^{88}$. Se puede estar de acuerdo con este juicio de Alföldy en el caso concreto de Mommsen. No así en el de Niebuhr ya que no apreciamos sus concomitancias con Syme, ni en lo que se refiere a su estilo ni a sus intereses históricos ${ }^{89}$.

${ }^{84}$ ALFÖLDY, Ronald Syme..., p.31.

85 GRUEN, Erich S., The Last Generation of the Roman Republic, Berkeley-Los Angeles-London, 1974, p. 49.

${ }^{86}$ CHRIST, op. cit., (n. 1).

87 ZANKER, op. cit., (n. 23).

88 ALFÖLDY, Ronald Syme..., pp. 33 s. Sobre la Römische Geschichte y su recepción en nuestro país, vd. DELGADO DELGADO, José A., «La obra de Theodor Mommsen en España. La traducción española de la Römische Geschichte» Gerión, 21 (2003), pp. 45-58.

89 Debo esta observación al Prof. José Delgado. 
Mommsen y Syme, por su parte, sí que poseen características convergentes. Ambos creían en la importancia de las fuentes para construir una ciencia de la Antigüedad con garantías. Postulaban la necesidad de que las disciplinas histórica y filológica fueran de la mano y formaran un todo unitario que ayudara a comprender mejor todos los matices del hecho histórico. Ambos eran firmes defensores de la importancia de la historia narrativa, de la historia factual. Y prestan gran atención al tratamiento de las personalidades más destacadas del período.

No es casualidad que la descripción de la personalidad de Octaviano en los dos autores sea muy similar. Mommsen y Syme experimentaron una cierta aversión hacia la figura del futuro Augusto. Desde luego, supieron ver más allá y no se dejaron fascinar por la imponente fachada ideológica del Principado. Asimismo, el estilo literario es excelente en ambos. Mommsen, galardonado con el Nobel de Literatura en 1902, es un modelo de la prosa histórica en alemán. Gibbon y Syme lo son en la lengua inglesa.

Como apunta Alföldy ${ }^{90}$, la historia de Roma como modelo de narrativa fue llevado al culmen de la perfección por el neozelandés en The Roman Revolution. Es cierto que algunas de sus afirmaciones precisan de una revisión que se viene efectuando en los últimos años. En especial, la imagen y el juicio histórico de Syme sobre Augusto y en concreto su metamorfosis de Dux a Princeps, necesitan una concienzuda matización. Tanto es así, que el mismo Syme reconsideró algunos aspectos sobre el personaje conforme avanzaba su propia vida y su investigación. Pero el libro es y seguirá siendo un clásico y los especialistas de la antigüedad romana tenemos una enorme deuda contraída con Sir Ronald Syme y su obra en conjunto, y muy especialmente, con su The Roman Revolution.

La aseveración que hace Alföldy acerca de La Revolución Romana como acabado ejemplo de historia narrativa merece ser matizada, en nuestra opinión. Syme fue un historiador en la más pura tradición de la «narrative history», en la estela de nombres tan excelsos como Gibbon o Macaulay. Pero algunos capítulos de $R R$ poseen un carácter rígidamente analítico, en tanto que son netamente prosopográficos. El propio Syme advierte, al comienzo del libro, que el lector poco interesado en estos temas puede obviarlos. Y es que quizá sea más difícil de lo que parece, a primera vista, reconciliar narración y prosopografía ${ }^{91}$

\section{CONCLUSIÓN}

El fellow de Trinity College tuvo desde fecha tan temprana como 1934 una opinión desfavorable sobre el joven Octaviano y como historiador se sintió siempre «republican in sentiment» ${ }^{92}$, influenciado por nombres como los de Salustio y

\footnotetext{
90 ALFÖLDY, Ronald Syme..., p. 41.

91 Agradezco al profesor Keith Bradley esta perspicaz observación.

92 SYME, RR, vii.
} 
Polión. Ya en 1934, en una importante reseña a un libro del italiano Mario Attilio Levi, que ha pasado inadvertida para los investigadores pero que es fundamental para entender al Syme «joven» anterior a RR, reivindicaba la figura de Marco Antonio calificando a Octaviano de «sickly and sinister youth» ${ }^{93}$.

$\mathrm{Y}$, sin embargo, a medida que pasaron los años Alföldy detecta, con enorme perspicacia, en los escritos de Syme un sutil cambio, algo más de tolerancia hacia el trabajo de otros colegas y hacia el personaje de Augusto. Incluso un poco más de humor: «less war and more humour». Al final de su recensión de 197994, Géza Alföldy cita una hermosa y muy precisa descripción de Tácito hecha por Syme que muy bien podría ser una descripción de él mismo:

"Tacitus is a subtle and sophisticated writer, heir to a long tradition, and writing for men of understanding. The situations he describes are permeated with all the ambiguities of high politics - and of human nature- in any age. His manner is majestic and reticent. Perhaps in himself a complicated character, perhaps not. Who can say?. Remote, austere and enigmatic, on a surface view, yet perhaps in no way a problem in his comportment towards Rome and the Caesars» ${ }^{95}$.

Estamos, pues, ante un Syme más tolerante que ganó en humor con el paso del tiempo. El neozelandés, transcurrido el ecuador de su vida dedicó sus esfuerzos a divertimentos como la Historia Augusta $^{96}$ y su visión de Augusto, el personaje central de su obra, fue adquiriendo un tinte cada vez menos siniestro, conforme esa benevolencia fue ganando terreno. Géza Alföldy lo percibió muy claramente: "In the couse of the years and decades, there is a clear tendency to tone down the harsh criticism given in The Roman Revolution „97.

Como conclusión, el tributo de Syme hacia Augusto fue siempre escueto, según Alföldy. Pero a lo largo de medio siglo adquirió un empaque cada vez más monumental. En concreto, estuvo cada vez más inclinado a reconocer la coherente organización que el Princeps proporcionó al edificio político que él mismo creó. O sea, el espectacular y positivo desarrollo de la administración imperial. El gentleman oxoniense parece haber experimentado, si no un sentimiento de simpatía, sí al menos cierta comprensión, cada vez mayor, con respecto a la difícil posición del emperador.

Syme supo ver como nadie la auténtica naturaleza del régimen creado por Augusto. De hecho en «The Apologia for the Principate», el capítulo final de su última gran obra The Augustan Aristocracy expone una crítica feroz de la «doctrine of the middle path», que es una de las más bellas y exactas descripciones del Principado como forma de gobierno:

93 SYME, Ronald, «From Octavian to Augustus. Mario Attilio Levi: Ottaviano Capoparte, 2 vols. Firenze, 1933» The Classical Review, 48 (1934), p. 78.

94 ALFÖLDY, Review..., p. 181.

95 SYME, Studies ..., p. 131.

96 Véase la divertida anécdota del encuentro en la High Street de Oxford entre Syme y el gran Eduard Fraenkel a fines de la década de los sesenta cuando el Ammianus and the Historia Augusta estaba en la imprenta: BOWERSOCK, Proceedings ..., p. 558.

97 ALFÖLDY, Principes..., p. 116. 
«Liberty but not licence, discipline without despotism. Not an exhilarating prospect, the middle path, so it appears. It is the recourse of the opportunist and the careerist. The other name is compromise or collusion. Yet such is the nature of political life. It exploits ambiguities, it seeks to have the advantages of both ways" ${ }^{98}$.

Todo un encontronazo con la realidad de lo que fue aquel sistema político. Y la expresión del máximo de tolerancia que un aristócrata y un demócrata, cosas que Syme siempre se consideró, pudo demostrar hacia un régimen de carácter autocrático con un gobernante en la cúspide que no estaba sujeto a control alguno.

Como Alföldy apuntó muy bien tras conocerlo durante un cuarto de siglo como amigo y como colega, la tarea de narrar los tiempos de Augusto, no le fue encomendada a Tácito, ni siquiera a Mommsen, sino al más grande historiador de Roma de nuestra época: Sir Ronald Syme. La gratitud de todos los historiadores de Roma hacia su figura debe ser permanente. Por su talento para narrar tan importante momento de la Historia, por su infatigable capacidad de trabajo, por su estilo literario que aún hoy nos asombra y nos lleva a leer y a releer con fruición sus páginas. Por ser, en definitiva, un auténtico princeps de la historia de Roma.

Otro princeps, amigo del neozelandés y recientemente fallecido, otro historiador eminente al que estamos dedicando estas páginas lo tuvo siempre meridianamente claro.

Uno de los elogios más hermosos que pueden escribirse de un historiador y de una persona fueron las siguientes líneas que Géza Alföldy dedicó, al final de uno de los textos que hemos analizado, a su amigo y maestro. Se me permitirá finalizar con ellas este trabajo:

«No author of an earlier age or afterwards described the history of the greatest Roman Princeps in a more coherent and fascinating manner than this Princeps of Roman Historians. He relentlessly unmasked the nature of authoritarian regimes for all times. At the same time, he was fortunate to live long enough not only to see both criticism and success of The Roman Revolution, but also to develop more tolerance towards the other side, contrary to his own aristocratic ideals. Not solely the first merit, which he shared, among others, with Ovid, but also the second induces me to end with the finale of his book dedicated to this poet: 'In short and to conclude', he 'won his war with Caesar'»99

98 SYME, $A A$, p. 453-454.

99 ALFOLDY, Principes..., p. 122. Tomando Alföldy el final de History in Ovid, p.229. El profesor Juan Manuel Abascal, en la necrológica de Alföldy que acaba de publicar en Veleia, nos proporciona el dato de que el sabio húngaro estaba ocupado en poner al día unas notas sobre Sir Ronald Syme en los días previos a su óbito: ABASCAL, Juan Manuel, «Géza Alföldy (1935-2011)», Veleia, 28 (2011), pp. 319328 , en concreto el dato figura en la p. 319. 
